\title{
Designing Inductive Instructional Activities in a Teacher Training Program to Enhance Conceptual Understandings in Science for Thai Science and Non-science Teachers
}

\author{
Pattawan Narjaikaew ${ }^{1, *}$, Varanya Jeeravipoonvarn ${ }^{2}$, Kanjana Pongpisanou $^{3}$, Dennis Lamb ${ }^{4}$ \\ ${ }^{1}$ Faculty of Education, Udon Thani Rajabhat University, Thailand \\ ${ }^{2}$ Faculty of Graduate Studies, Udon Thani Rajabhat University, Thailand \\ ${ }^{3}$ Udon Thani Primary Educational Service Area Office 1, Thailand \\ ${ }^{4}$ Department of Education, Southwest Minnesota State University, USA
}

Copyright $\mathrm{O} 2016$ by authors, all rights reserved. Authors agree that this article remains permanently open access under the terms of the Creative Commons Attribution License 4.0 International License

\begin{abstract}
Teachers are viewed as the most significant factor affecting student learning. However, research in science education showed that teachers often demonstrate misunderstandings of science very similar to students. The purpose of this research was to correct conceptual difficulties in science of Thai primary school science and non-science teachers using inductive learning activities in a teacher training program. An eighteen hour teacher training program was designed to address conceptual difficulties in science based on research findings of three science concepts including force and motion, simple electric DC circuits, and astronomy. A pre- and post-test with 15 multiple-choice questions for each of those concepts were administered to thirty volunteer primary school science and non-science teachers in 2014. Data was entered into Excel and analyzed for a correct percentage for each question. There were overall gains in understanding between the pre- and post-tests for these three concepts when teachers were taught by inductive methods. It suggests that using inductive learning activities can be used as a meaningful teacher training program for science and non-science teachers to correct conceptual difficulties in science.
\end{abstract}

Keywords Inductive Instructional Activities, Conceptual Understanding, Teacher Training Program, Thai Science and Non-science Teachers

\section{Introduction}

One of the best-known statements for American Education in the 21st Century of the American Commission on Teacher Education is that "The quality of a nation depends upon the quality of its citizens. The quality of its citizens depends not exclusively, but in critical measure upon the quality of their education; the quality of their education depends more than any single factor, upon the quality of their teacher"[1]. Education is viewed as having an important role in helping young people achieve their goals in life. It is widely agreed that students' achievements are based on the teachers' knowledge and capabilities in teaching, in the other words, one of the most important factors affecting student achievement is highly qualified teachers [2][3]. As a result, teacher education reform is one of the most important agenda items of almost every country in the world. Many of the current reforms promote the professional development of highly qualified teachers. For example, this is one of the goals of the No Child Left Behind Act (NCLB). A highly qualified teacher is one who has demonstrated subject matter knowledge and teaching skill in each assigned core academic subject area [4].

Teacher effectiveness is generally referred to in terms of a focus on student outcomes, as well as teacher behaviors and classroom processes that promote desired student outcomes such as good grades, better attitudes, and improved skills [5][6]. However, teachers are not only seen as the most important person in helping students develop understanding, but they are also viewed as major obstacles to student learning. Many traditional teacher education programs have been criticized for having little connection to practice, teaching of theory separately from its applications as a result of having little academic preparation [7]. Teacher experiences from teacher education programs influence their understanding of teaching, therefore, they often teach in ways similar to how they were taught [8]. Manisha Das [9] mentioned that no teacher education program can prepare teachers for all the situations they will encounter. 
Teachers' knowledge is generally considered to be the strongest influence on student learning outcomes. This means a number of things in educational research. For example, Shulman [10] categorized teacher knowledge into seven types including: content knowledge, general pedagogical knowledge, curriculum knowledge, pedagogical content knowledge, knowledge of learners and their characteristics, knowledge of educational contexts, and knowledge of educational aims, purposes, and values. Grossman and Richert [11] divided teacher knowledge into two domains, i.e., knowledge of the subject matter to be taught and knowledge of general pedagogical principles and skills. Abell [12] classified teacher knowledge into three domains as follows: 1) subject matter knowledge (SMK), pedagogical knowledge (PK) including knowledge of instructional principles, classroom management, learners and learning, 2) educational aims, and 3) pedagogical content knowledge (PCK) including, knowledge of learners, knowledge of curriculum, knowledge of instructional strategies, and knowledge of assessment.

Science education is recognized as being important for all people in a world of rapid change. Since there are many issues related to science and technology in the age of globalization with its information and communication revolution, people are therefore expected to attain knowledge and understanding of scientific concepts and processes required for personal decision making, and for participation in civic and cultural affairs [13]. To achieve a scientifically literate citizenry, nations need effective science teachers who are able to facilitate science learning for all students. As discussed above, teachers' knowledge is seen as the strongest factor affecting student learning outcomes. Additionally, many students claim that science is difficult to understand. Research on science education found that even after instruction, students' misconceptions seem to be consistent [14][15]. Teachers' academic skills measured by scores on achievement tests were significantly correlated with student achievement [16]. Some research results seem surprising that teachers also demonstrate misunderstanding of science in ways very similar to their students, especially for elementary school teachers [17]. Therefore, teachers with low content knowledge contribute to students' confusion and misunderstanding. Conceptual difficulties in science of in-service teachers need to be corrected through suitable training programs.

\section{Background of the Study}

Before the education reform in Thailand during the reign of King Rama V, boys were taught by Buddhist monks about reading, writing, Buddhist preaching and morality, while girls were taught an occupational skill by their mothers and grandmothers. The palace was a place for educating royal and noble family members. Therefore, monks and parents played roles as teachers in an educational system that had no policy [18]. To avoid being colonized, several systems in country were reformed as a modern nation. The new education system, Western-style formal education, was begun with the establishment of schools for all Thai children. Establishing schools lead to the creation of teacher training institutions. The first education reform in Thailand was initiated in the reign of King Rama V. Thailand has undergone many education reforms and changes, which have directly changed teacher education programs.

Most recently, two teacher preparation systems were developed under the regulation of the Teachers Council of Thailand on Professional Standards and Ethics B.E. 2548 (2005). The first system, requires undergraduate teachers to complete a five-years Bachelor's degree in education with minimum of credits as follows: 30 credits in general education courses, 50 credits in pedagogy courses, 74 credits in subject-matter courses, and 6 credits of elective courses plus one year of student teaching. The second teacher preparation system requires that graduate teachers complete a bachelor's degree in non-educational fields before completing a one year graduate diploma program with 24 credits in pedagogy courses, plus one year of teaching experience. In 2014, the regulation of the Teachers Council of Thailand on Professional Standards and Ethics B.E. 2548 (2005) was modified to include the regulations of the Teachers Council of Thailand on Professional Standards and Ethics B.E. 2556 (2013). There are six teacher preparation systems: a five-years undergraduate teacher program, a six year integrated bachelor's and master's degree program, a one year graduate diploma program, a two-year master's degree in teaching program, a four-year of integrated master's and doctoral degree program, and a three-year doctoral degree program [19].

After World War II, science has increasingly become a part of multiple disciplines. Currently, we live in a world filled with the products of scientific inquiry and everyone needs to use scientific information to make choices that arise every day. Consequently, scientific literacy has become a necessity for everyone [13]. In Thailand, science education has undergone reforms and changes. The Institute for the Teaching Science and Technology (IPST), which was officially established in 1972, plays a major role in developing science and mathematics curricula for all the levels of schooling. However, at the early stages of development, science training in primary schools was integrated with social studies and civic education in the work-oriented experience group. It was not taught in its own right [20]. Science became a compulsory subject at the primary school level when the Basic Education Curriculum B.E. 2544 (A.D. 2001) was implemented in 2003.

Like many other countries, Thailand has been facing major problems related to the quality of in-service teachers, although most Thai primary and secondary school teachers had completed undergraduate study programs. The reason is likely that the teacher preparation programs provided too little academic learning and little work experience. Consequently, the Teachers' Council of Thailand Board had to improve professional standards. Moreover, there are many 
teachers assigned to teach classes in fields that do not match their educational background [21]. As a report of monitoring and evaluation of Thai education management under the national education policy in 2013, more than 36 percent of Thai teachers were assigned to teach classes outside their fields of expertise. Based on the data report from the TIMSS2011 (Trends in International Mathematics and Science Study) which measured mathematics and science achievement of students at grades 4 and 8 , about $33 \%$ of grade 4 Thai students were taught by out-of-field science teachers as were about $21 \%$ of grade 8 Thai students [22]. Since many Thai primary school teachers are not science majors, many of them still emphasize science content coverage using traditional teaching strategies. Related research findings on elementary school science teachers in other countries found that they lacked understanding of scientific concepts, especially in areas such as physics, earth science, and astronomy. Thus, they teach very little in these areas or avoid teaching those topics [23].

\section{Significance of the Study}

In order to solve the problems related to the quality of teachers, teacher training programs have often been developed by many different people or educational institutions with different purposes. In Thailand, there are 56 faculties of education at 56 state universities and 40 faculties of education at Rajabhat universities that take responsibility of teacher preparation for schools in their service areas [22]. The Faculty of Education, Udon Thani Rajabhat University (UDRU) has been dedicated to preparing and training teachers to meet the education needs since 1923. With cooperation between UDRU science educators, a school science supervisor, and school science teachers in the Udon Thani Primary Educational Service Area Office 1 (UDPESAO1), three conceptual difficulties in science for primary school teachers were identified. These included force and motion, simple DC electric circuits, and astronomy. They were selected in developing a teacher training course to improve teacher understanding of these concepts. Although the main purpose of the training program was intended to correct teachers' conceptual difficulties in science, processes of inquiry were applied to create instructional activities to help them understand how science knowledge is constructed. The teacher training program was conducted during weekends to avoid necessitating teacher absence from their classrooms.

Traditional science and engineering instruction is taught by deductive processes. The instructor introduces a topic by providing general principles, then represents the principles with derived equations, shows applications of the equations, have students practice a few situations, and ends up with doing test [24]. In contrast, the inquiry approach to science relies heavily on the induction process, which is as follows: hypothesizing about the nature of a problem based on evidence, designing experiments to test the hypothesis, observing and measuring, recording and interpreting, inferring and predicting, and finally generalizing [25]. Many scientists, especially the experimentalists, have their works rely on inductive processes. However, the theoretical scientists (e.g., Albert Einstein - Theory of Relativity) have their work rely on the deductive processes. Although Inductive teaching and learning encompasses a range of teaching methods including inquiry-based learning (also known as inquiry-guided learning or guided inquiry), discovery learning, problem-based learning, project-based learning, case-based teaching, and learning cycle-based teaching. The key attributes of this approach enables students to experience the processes of knowledge creation in which the common characteristic of student-centered approaches, active learning, development of self-directed learning, and a constructivist theoretical basis [26].

There are two main forms of constructivism, i.e., cognitive constructivism and social constructivism. The main tenet of cognitive constructivist learning draws heavily on Piaget's theory of cognitive development. The learners construct their own individual understanding of the world. The teacher should facilitate a change in student's view toward scientifically based views. On the other hand, the social constructivist aspects of understanding and learning are increasingly important because knowledge construction requires an active process of interpretation in group discussions, or in a learner's interaction with groups of learners. Teachers need to plan activities that allow students to find what they are thinking to help them build on their understandings [27] and promote social activities with meaning negotiated from multiple perspectives [28].

Taking into account educational literature, we designed the learning and teaching process for a teacher training program in an inductive way. The main reason was to enable primary school science teachers to follow the way of discovering knowledge by scientists, which conceptual knowledge was constructed based on making observations and collecting data. We believe that adopting an inductive process in science learning activities should be a step forward in the right direction to enhance teachers' conceptual difficulties in science, which is related to the nature of science knowledge creation.

\section{Objective of the Study}

To study the effectiveness of using inductive learning in a teacher training program to correct conceptual difficulties in science of Thai science and non-science teachers.

\section{Methodology}

The pre-experimental research with a one group pre-test-post-test design was used in this research. The participants, research instruments, and data collection are listed as follow: 


\subsection{Participants}

The participants involved in this 2014 study in were thirty volunteer primary school science teachers under the Udon Thani Primary Educational Service Area Office 1, including 18 science teachers with earned degrees in science and 12 non-science teachers who had not studied science.

\subsection{Inductive Learning Activities in Science}

Regarding teacher and UDPESAO1 needs, force and motion, simple electric DC circuits, and astronomy were selected as topics to develop instructional activities based on inductive processes. Six hours of time was allocated to each daily instructional activity. The instruction was entirely done during a three-day weekend in this teacher training program. In designing the instructional activities, Leach and Scott's work [29] was used as a guide to planning the instructional activities in the following way: analysis of the science knowledge in the curriculum to be taught, identification of misconceptions or conceptual difficulties, identification of learning demands, and organization of instructional sequences that relied on inductive processes.

\subsubsection{Lesson on Force and Motion}

By analyzing the science knowledge about force and motion, the main concepts that primary school science teachers needed to learn were: science terms used to describe the motion of objects (position, rate, distance, displacement, speed, velocity, and acceleration), the relationship between force and motion, laws of motion (Newton's first, second and third laws), projectile motion, and circular motion. Common misconceptions about force and motion were the following: 1) motion is always caused by force, if there is no force acting on the object, it does not move, 2) force is proportional to velocity, 3) gravitational force is exerted on an object not only when it fall, but also while it is being raised, 4) heavier objects fall more quickly than the light ones, 5) a greater mass exerts a greater force, and 6) objects in circular motion tend to move away from the center of circle due to the centrifugal force [30]. The learning demand of force and motion training was identified as primary school science teachers needing to: 1) experiment and explain distance, speed, displacement, velocity, and acceleration of objects in motion, 2) experiment and explain effects of forces acting on objects, 3) explain the resultant force acting on a stationary object or an object moving at constant velocity, 4) explain acceleration and effects of a resultant force acting on an object, 5) experiment and explain action and reaction forces, and apply this knowledge, and 6) observe and explain projectile and circular motion [31]. Five major steps of the inductive method, known as the Herbartain method of teaching [32], were used to organize instructional activities in which each is shown as follows:

Step 1: Preparation. The preparation phase involves motivating the learners by raising preliminary questions:
- What are the words used to describe the motion of objects?

- Do moving objects always need force? Why?

Step 2: Presentation. The presentation phase involves analyzing the motion of objects by observing sets of data from:

- Ticker tape diagrams that were used to support learners in forming concepts of position, rate, distance, displacement, speed, velocity, and acceleration by analyzing what the distance between dots on ticker tapes tell them about the object motions.

- Video demonstration of a glider floating on the air track (experimental apparatus with minimal interference by frictional forces) at different inclination angles. These video demonstration sets were used to support learners in understanding the relationship between force and motion by analyzing the distance between dots (tracking the position of the glider's position/time) on the video screen.

- Video demonstration of a glider floating on the air track linked to a string passing over a pulley with various hanging weights the other end. These video demonstration sets were used to support learners in understanding the relationships among force, mass, and motion (Newton's first and second laws of motion).

- Video demonstration of 2 balls falling from the same vertical height, which one is released from rest while the other is projected horizontally at the same time and its motion forms a parabolic path. These video demonstration sets were used to support learners in understanding projectile motion.

- Video demonstration of an ice skater being tied to a string while moving in a horizontal circle. This video demonstration was used to support learners in understanding the circular motion.

- Demonstration of one person pushing a wall while wearing a pair of roller blades, two people pushing each other while wearing a pair of roller blades; one person holding of two spring balances that are connected and suspended with a kilogram mass. These demonstrations were used to support learners in understanding Newton's third law of motion.

Step 3: Comparison and Abstraction. This third step requires learners to analyze and organize data gathered from the second step by determining related or contrast elements, and cause-and-effect links between two or more given phenomena. After observing the distance between dots on ticker tapes, primary school science teachers should be able to determine:

- Which objects move faster or slower? A constant distance between dots represents a constant velocity and no acceleration. A changing distance between dots represents a changing velocity or acceleration.

- As a glider is pushed it moves smoothly, the distance between dots is constant, the velocity of the glider is 
also constant. As the glider accelerates down the inclined track, the distant between dots increases with time because it is moving at a higher velocity. Higher inclination results in greater acceleration.

- As a small hanging mass moves down, it accelerates. As the mass increases, the distance between dots increases with its acceleration. With the same hanging weight, the glider's mass increase, the distant between dots becomes less because acceleration decreased. Acceleration is inversely proportional to the mass.

- A ball dropped vertically and one with a projected horizontal motion both reach the surface at the same time. They fall vertically with the same acceleration. For a ball with a parabolic path, a constant distance between dots in the horizontal direction represents a constant velocity or no acceleration, while the distant between dots increased with time downward (changing velocity) representing acceleration.

- As an ice skater tied to a string keeps moving in a horizontal circle, the direction of velocity is always changing, represents acceleration toward the center of the circle at any point of time. When the string is cut, the ice skater moves in a path tangential to the circle.

- A boy on a pair of roller blades moves backward after pushing a truck representing the opposite force direction exerted on him. Two boys on roller blades move apart after pushing each other representing forces acting in opposite directions. Two identical balances read of 9.8 Newton's force represents the downward force exerted by the mass is equal to the upward force exerted by a person's hand.

Step 4: Generalization. The fourth step requires learners conclude, create, or represent the elements found from the third step into core concepts, common principles, mathematical formals, general cause-and-effect relationships. After class discussion, primary school science teachers should know the following:

- Physical quantities including position, time unit, distance, displacement, speed, velocity, and acceleration are used to describe the object's motions. An object moving with constant velocity means that it is moving in a straight line at a constant speed, with no acceleration. An object moving with a change in velocity or direction means that it is moving with acceleration. An object moving in a circle with constant speed has acceleration.

- Without resistance, forces always cause change motion. Changing motions means varying velocity (magnitude or direction) or acceleration. Net force is directly proportional to acceleration and mass. A stationary object or one moving in a straight line with constant velocity has no force exerted upon it (Newton's first law). An object moving with changing velocities or acceleration has a force exerted on it. Any object that is being accelerated has a force acting upon it (Newton's second law).
- For parabolic motion of projectiles, there is no force exerted on an object moving horizontally. Force only acts in the vertical direction.

- For uniform circular motion, force is always exerted on an object toward the center of the circle path at any time.

- For every action force there is always a reaction force that is equal in magnitude and opposite in direction (Newton's third law).

Step 5: Application. This fifth step requires that learners apply these generalizations to new situations. Primary school science teachers were asked to describe the motions of a moving coin in the air, a ball after being shot by a football player, motorcyclists riding around a cylindrical wall.

\subsubsection{Lesson on Simple Electric DC Circuits}

Primary school science teachers needed to be taught how to build a complete DC circuit, to use electrical measuring instruments, how to connect electrical bulbs in series and parallel, connection of electrical cells in series and parallel, and electric power.

Common misconceptions and difficulties about simple DC circuits include confusion about terms. They also do not understand that a battery is a constant current source, that meters are circuit elements, and that two batteries in parallel provide more voltage and current. In a circuit with multiple bulbs, circuits with fewer bulbs are brighter than those with more bulbs, and that the brightness of each bulb depends on its order in a circuit [33].

The learning demand for simple electric DC circuit was identified as primary school science teachers needing to: 1 ) experiment and explain current, voltage, resistance, power, 2) experiment and explain that electricity is a form of energy, 3 ) experiment and explain a simple electrical circuit, 4) experiment and explain the connection of light bulbs in series and parallel, 5) experiment and explain the connection of electrical cells in series and parallel, and 6) experiment and explain relationship between voltage, current, and resistance [31].

The inductive method was used to organize instructional activities for simple electric DC circuits as follows:

Step 1: Preparation. The preparation phase involved motivating the learners by raising preliminary questions:

- How many bulbs can we light a bulb with a battery and a single wire?

- Compare the brightness of 2 bulbs within series and parallel circuits. Which is brighter? Why?

- Compare the brightness of a bulb connected to 2 cells within series and parallel circuits? Which is brighter? Why?

- How can we connect a meter into circuits to determine the current and voltage of a circuit?

Step 2: Presentation. A boxed set of materials including 2.5 volt electric bulbs, wires, $1.5 \mathrm{~V}$ dry cells, and a meter 
was provided to a group of learners. Groups were assigned to determine how to construct simple electric DC circuits in the following situations:

- Determine the possible ways to light a bulb with a battery and a single piece of wire.

- Determine how to connect an ammeter and voltmeter to measure the current and voltage in a way that does not affect the brightness of the bulbs in a circuit?

- Observe the brightness of the bulbs and meter readings for circuits (1) - (4) as shown in Figure 1. These situations are: 1) two bulbs in series with a battery, 2) two bulbs in parallel with a battery, 3) two batteries in series with a bulb, and 4) two batteries in parallel with a bulb.,
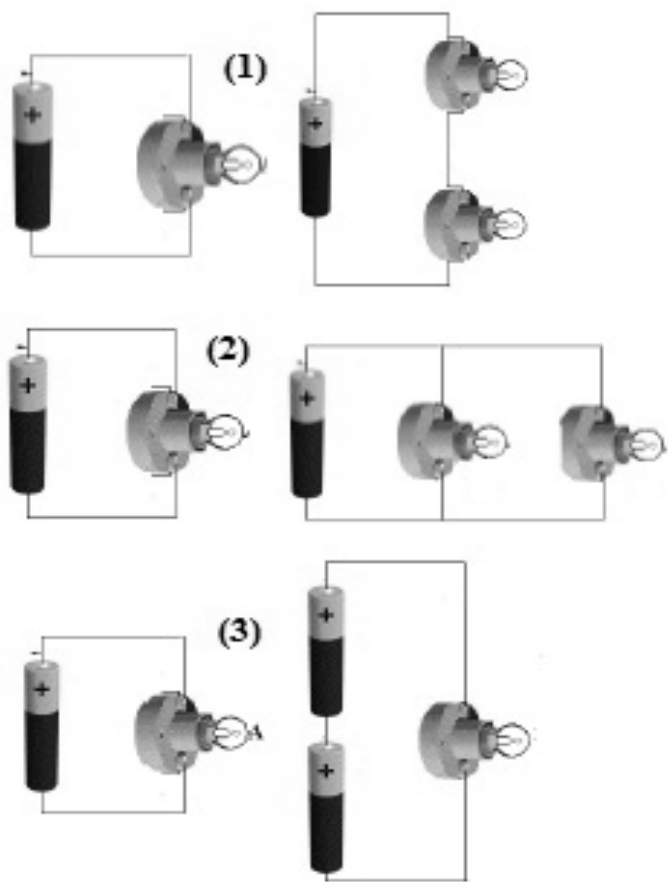

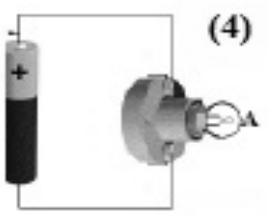

(5)

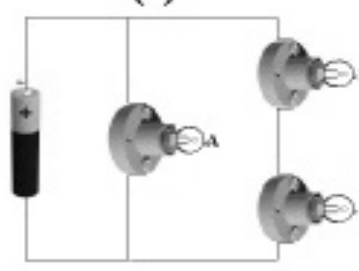

(6)

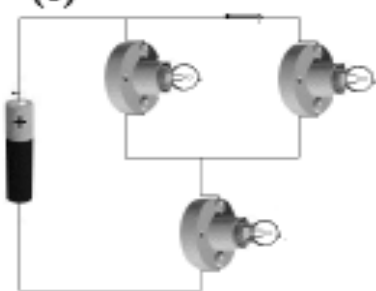

Figure 1. Simple electric DC circuits

Step 3: Comparison and Abstraction. After constructing simple electric DC circuits, primary school science teachers should be able to determine the following:
- After observing a light bulb construction, they should understand that there are four arrangements of a light bulb, a single battery and a single piece of wire that will light a bulb as shown in Figure 2. Both terminals of a bulb must be connected externally to the two terminals of the battery.
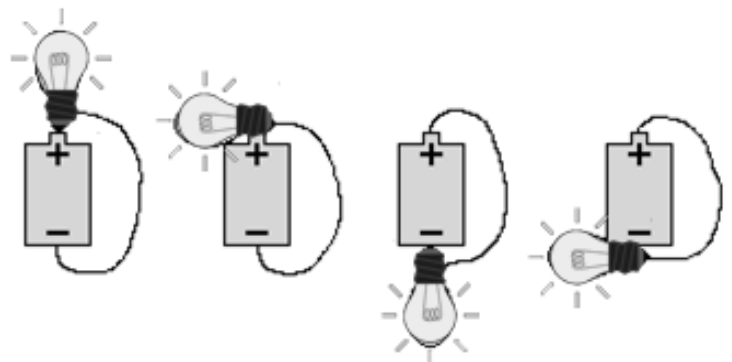

Figure 2. Four arrangements to light a bulb with a battery and a wire

- An ammeter is connected in series in the circuit and if it is connected across a bulb, the bulb dims. When a voltmeter is connected across a bulb, the bulb is bright. However, when the voltmeter is connected in series, the bulb is dim. An ammeter is connected in series with a device to measure its current, while a voltmeter is connected in parallel with a device to measure its voltage.

- After adding another identical bulb to circuit with a single bulb, it is seen that two bulbs in series decrease the brightness and halve the voltage cross each bulb, but the same current travels through each bulb and the battery. Two bulbs in parallel provide the same brightness, voltage and current, but double current through a battery. The voltage across a battery is the same in all these cases.

- After adding another battery to a single battery circuit with a single bulb it is found that for two batteries in series, the voltage differences of battery terminals and the brightness of a bulb increases. With two batteries in parallel, the voltage differences of battery terminals and the brightness of a bulb are the same as in a single bulb circuit with a single battery.

Step 4: Generalization. After class discussion, primary school science teachers should know that:

- The simplest complete circuit consists of a piece of wire from one end of a battery to the other. In other words, a complete circuit consists only of batteries and resistive elements.

- Electricity from batteries can do work, therefore, the electricity is a form of energy.

- Connection of light bulbs in series provides the same current through the bulbs as is passed through a battery, but the voltage is divided between the bulbs. When connecting light bulbs in parallel, the current from a battery is divided before being passed through each bulb, but the voltage across each bulb is the same as for the battery. 
- Connection of electrical elements in series increases both the current and the voltage of the loads in the circuit. Connection of electrical cells in parallel gives the same current and voltage of the loads in the circuit.

Step 5: Application. Primary school science teachers were asked to rank the brightness of bulbs in circuits (5) (6) circuit as shown in Figure 1 and describe the results.

\subsubsection{Lesson on Astronomical Phenomena}

The curriculum science knowledge in astronomical phenomena needed by primary school science teachers consists of: 1) Earth's rotation causes the apparent rising and setting of the Sun, days and nights, 2) seasons are arise because by each part of the Earth receives different amount of energy from the Sun since the tilt of the Earth's rotational axis is away or toward the Sun as it travels around the Sun, 3) as the Moon orbits the Earth and as the Earth orbits the Sun, so we see the reflection of Sunlight from the Moon's surface differently each night, and 4) and eclipse occurs when the Earth, the Moon, and the Sun are in a straight line. A solar eclipse occurs when the Earth moves into the Moon's shadow and a lunar eclipse occurs when the Moon moves into the Earth's shadow.

Common misconceptions about astronomical phenomena are that: 1) day and night are caused by the Sun going around the Earth, 2) the Sun rises exactly in the east and sets exactly in the west every day of the year, 3 ) the earth is farther away from the Sun in winter and closer in summer, 4) the phases of the Moon are caused by the shadow of the earth, and 5) the Moon makes its own light [34].

The learning demand of the astronomical phenomena was identified as primary school science teachers needing to: 1) observe and explain the rising and setting of the Sun and the causes of day and night, and 2) construct a model and explain the cause of seasons, phases of the Moon, a solar eclipse, and a lunar eclipse.

The inductive method was used to organize instructional activities in astronomical phenomena as follows:

Step 1: Preparation. The preparation phase involved motivating the learners by raising preliminary questions:

- What causes day and night?

- What causes the seasons? Does the Sun rise and set at the same point?

- What causes the Moon phases?

- What causes solar and lunar eclipses? And how they are different?

Step 2: Presentation. A set of materials including globes, flash lights, pieces of paper, ping-pong balls, and guided procedure sheets was provided to a group of learners. They were assigned to learn what causes astronomical phenomena such as the following:

- Determine what causes day and night by using a globe and flash light.

- Find out what causes the seasons using a globe and flash light.
- Find out what causes the Moon phases by using a flash light and a ping-pong ball.

- Find out what causes solar and lunar eclipses by watching a video.

Step 3: Comparison and Abstraction. After completing astronomy tasks, primary school science teachers should be able to determine:

- A stationary flashlight beam shining on a rotating globe shows that one side is illuminated, while the other side does not receive light. This shows that the rotation of the Earth causes day and night.

- After moving a tilted globe around a flashlight, a flashlight beam shown directly on the center, above the center, center, and below the center of a globe. The areas that receive more direct light would tend to be hotter. The areas at the center, above, and below the center of the globe receive more direct light at different times, while the globe travels around the flashlight. This shows the tilt of the earth's axis as the globe goes around the Sun. Regions of direct illumination change and this causes the seasons.

- Observations were made of various illuminations of ping-pong balls held by a teacher, while walking in a circle around the observer. The light source represents the Sun, the ping-pong ball represents the Moon. The Sun's light is shining only on one side of the Moon while the other side does not receive the light. Since the Moon is located above the observer on the earth, while it goes around the Earth, we see the various illuminated shapes of the Moon.

- Observations were made of the shadow on a Moon and on the Earth, while the Earth travels around the Sun and while the Moon moves around the Earth. Solar eclipses occur when the Moon blocks the Sun's rays and casts a shadow on Earth, while lunar eclipses occurs when the Earth blocks the Sun's rays and casts a shadow on the Moon.

Step 4: Generalization. For astronomical concepts, all of seasons, Moon phases and eclipse concepts were elucidated in the third step.

Step 5: Application. Primary school science teachers were asked to describe, directions on the earth, the path of the Sun across the sky throughout a year, and tidal phenomena.

\subsection{Data Collection Tools}

The pre- and post-test with 15 multiple-choice questions for each of those three concepts were used to address the teachers' understanding of force and motion, simple electric DC circuits, and astronomical phenomena. Force and motion questions were from the Force Concept Inventory (FCI) [35] and the Force and Motion Conceptual Evaluation (FMCE) [36]. Simple DC circuit questions were from the Determining and Interpreting Resistive Electric Circuits Concepts Test (DIRECT) [33]. The astronomical phenomena questions were developed by the researchers. 


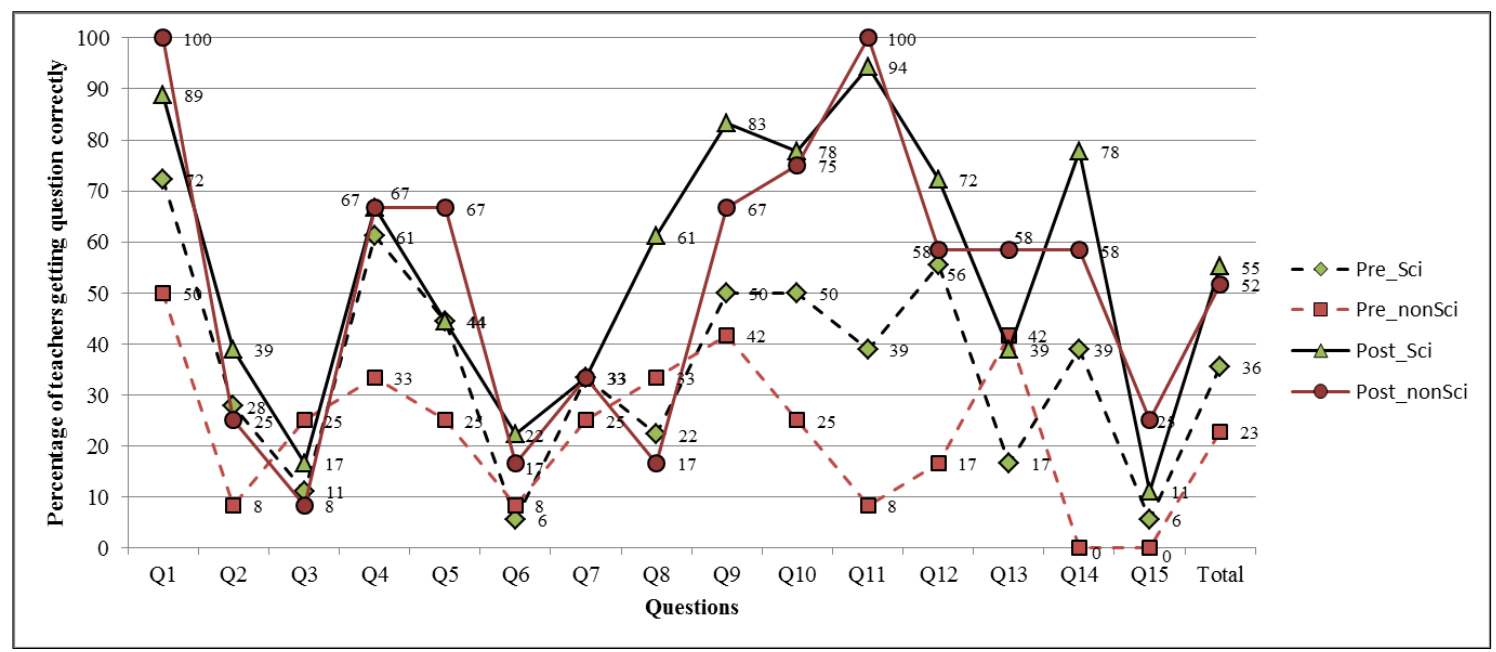

Figure 3. Pre and post-test results for teacher's responses on the Force and Motion test

\subsection{Data Analysis}

For analysis purposes, the test data was entered into Excel and analyzed for a correct percentage for each question in the pre- and post-tests.

\section{Research Findings}

This section focuses on the evaluation of primary school science and non-science teachers' understanding of science concepts before and after participating in a training program.

\subsection{Teacher Conceptual Understanding of Force and Motion}

The questions on force and motion were combined into six topic sets which were: the relationship between force and motion (Q10 and Q15), the Newton's First Law of motion (Q2 and Q12), the Newton's Second Law of motion (Q1 and Q13), the Newton's Third Law of motion (Q3- Q8), projectile motion (Q11 and Q14), and uniform circular motion (Q9). To determine how science and non-science teachers' understanding of force and motion concepts before and after participating in this training activity, a correct percentage for each question in the pre- and post-test of teacher's responses on the test was presented. The results of the analysis were shown in Figure 3.

An analysis of the test indicated that there was a small number of correct percentages overall of the science and non-science teachers getting the question correctly for the pre-test. After seeing typical responses to the question 3, 6, 8 and 15 in which fewer than $25 \%$ of these teachers answered questions in ways that are consistent with a Newtonian view of the world, either before or after traditional instruction. It seems that both science and non-science teachers seem to have some confusion about the Newton's Third Law and the relationship between force and motion after the intervention. As their answering in Question 3 and Question 6, it suggests that they still believe that the faster objects exert greater force on the lighter one and $50 \%$ of non-science teachers believe that heavier object's exert the greater force on the lighter object (Question 8). As shown by the results in question 15, the results show that more than $12 \%$ of the science and $26 \%$ of the non-science teachers had incorrect ideas that a force will produce motion or a constant force produces constant velocity. However, the overall percentage of correct answers for the science and non-science teachers were over a half ( $55 \%$ of science teachers and $52 \%$ of non-science teachers) for the post-test, respectively. These results support the usefulness of using inductive activities to enhance conceptual understandings in force and motion for Thai science and non-science teachers.

\subsection{Teacher Conceptual Understanding of Simple Electric DC Circuits}

The 15-item multiple-choice questionnaire from the studies of Engelhardt and Beichner (2004), and, Shaffer and McDermott (1992) was administered to Thai science and non-science teachers. The percentage of elementary teachers answering each question correctly is shown in Fig 4. The questions grouped into five topic sets which were: the interpreting diagrams of a variety of circuits $(\mathrm{Q} 2, \mathrm{Q} 7$ and Q11), the brightness of light bulbs (Q4, Q8, Q10, Q14 and Q15), the concept of power (Q1, Q6 and Q12), the concept of voltage (Q3 and Q13), and the concept of current (Q5 and Q9). 


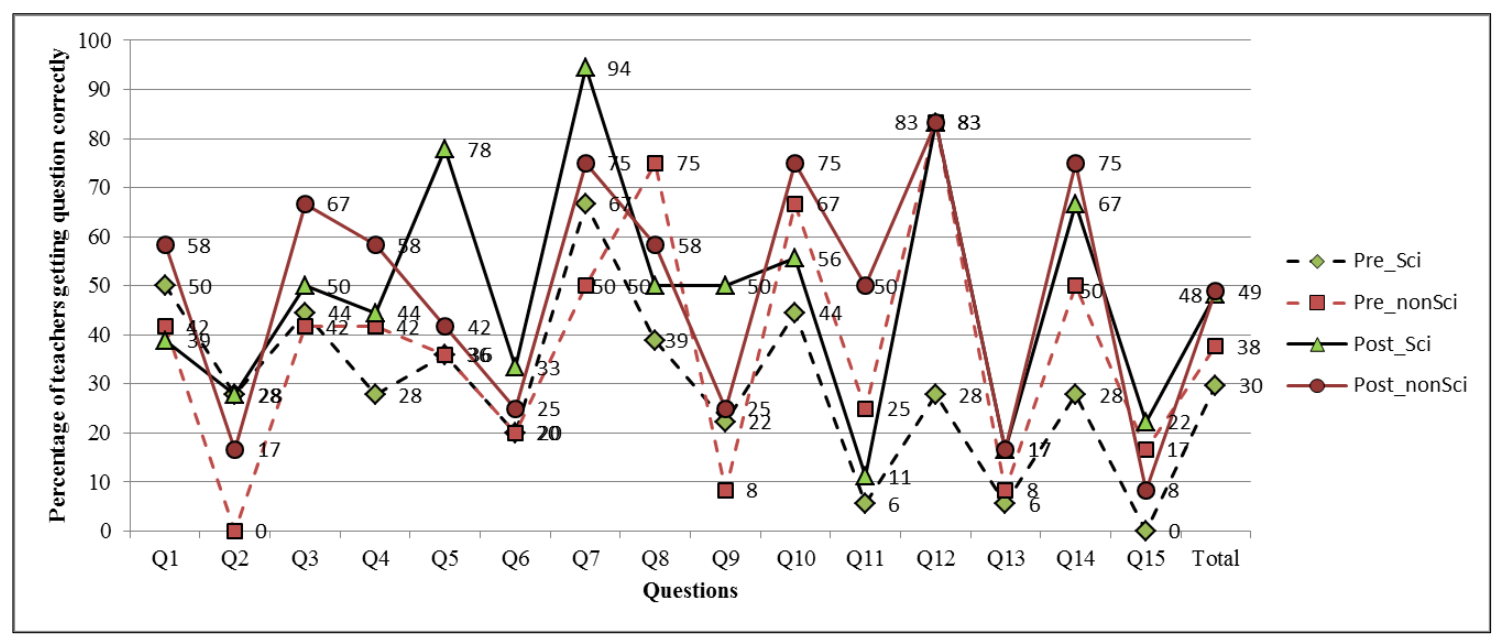

Figure 4. Pre and post-test result for teacher's responses on the Simple Electric DC Circuit test

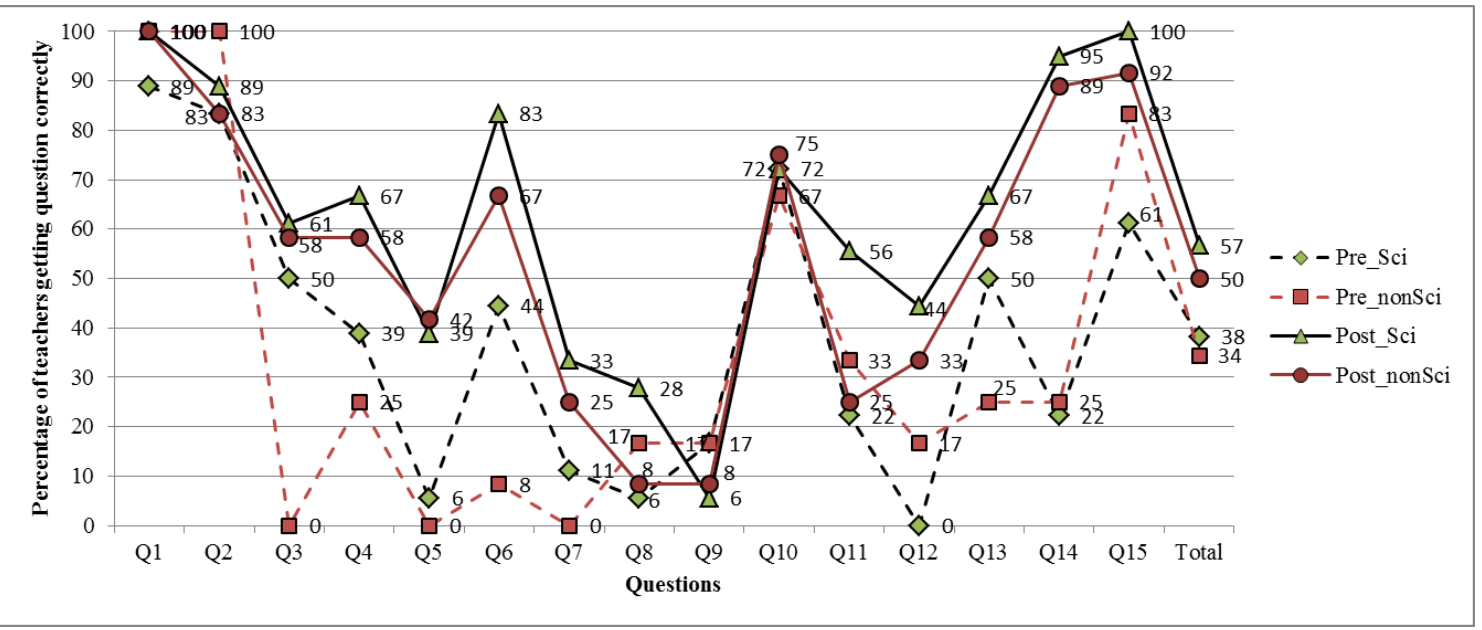

Figure 5. Pre and post-test result for teacher's responses on the Astronomical Phenomena test

To analyze teachers' understanding of simple electric DC circuit concepts before and after the inductive learning activities in teacher training, a comparison of the percentage of their correct answers on the test before and after teaching was made. After the intervention, the percentage of correct responses was quite low for Questions 2 and 11 with interpreting diagrams of a variety of circuits. They usually answered correctly in the case of a simple circuit with 2 bulbs, but could not do so when the circuits were drawn in an unconventional manner (as in Question 11). In Questions 13 and 15 , there was a low percentage of correct answers, which dealt with the concept of the relative brightness of bulbs both before and after participating in the activity. However, nearly a half ( $48 \%$ of science teachers and $49 \%$ of non-science teachers) answered overall questions correctly for the post-test, respectively. An analysis of the test indicated that there was an overall gain in understanding of simple electric DC circuits between the pre- and post-tests of the science and non-science teachers when they were taught by the inductive method.

\subsection{Teacher Conceptual Understanding of Astronomical Phenomena}

This section details teacher understandings of astronomical phenomena. The questions on astronomical phenomena were categorized into five topic sets which were: day and night (Q1 and Q2), the sun-earth-moon geometry model (Q3, Q4 and Q5), the seasons and the path of the sun across the sky (Q6, Q7, Q8, Q9 and Q11), the moon phases (Q10, Q12 and Q13), and the eclipses (Q14 and Q15). Figure 5 displays the average percentage of correct answers of the science and non-science teachers on the pre-test and post-test.

The primary school science and non-science teachers' performances on the conceptions of the astronomical phenomena were quite low for the pre- test (excluding Question 1 and 2). After the intervention, the percentage of correct responses was quite low for Questions 8 and 9 dealing with the seasons in the northern and the southern hemispheres. Fewer than $20 \%$ of the science and non-science teachers had the correct idea about what cause the seasons. Nearly 100 percent of these teachers understood what caused the day and night both before and after the intervention. And nearly 100 percent of these teachers understood what caused the eclipses after the intervention (Question 14 and 15). An analysis of the 
astronomical phenomena test indicated that there was an overall gain in understanding between the pre- and post-tests when teachers were taught by inductive methods.

\section{Conclusion and Discussion}

The study aimed to study the effectiveness of using inductive learning in a teacher training program to correct the conceptual difficulties in science of Thai science and non-science teachers. The common misconceptions in force and motion for the primary science and non-science teacher are: force is proportional to velocity of motion; the moving object exerts more force than the stationary object; gravitational force exerts on the object only when it moves down, but while it is on the way up, the force is from a person's hand. The Thai science and non-science teachers' conceptual difficulties about force and motion seem similar to the research findings in physics education [30] [35]. The teachers' difficulties with conceptual questions about simple electric DC circuits are as follow: interpreting diagrams of a variety of circuits including series, parallel, and combinations of series and parallel circuits; the position of bulbs affected its brightness regardless of how they are connected. The common misconceptions teachers hold are concerning the brightness of each bulb depending on its order in a circuit and how the number of bulbs affects their brightness related to research findings in the simple electric DC circuits [33] [36]. The most common misconceptions about astronomy phenomena are: the earth's seasons are caused by the distance of the earth to the sun; the plane of the earth's orbit around the sun lies in the same plane as the moon's orbit around the earth.

Based on the findings obtained in the study, using inductive learning activities can be used as a meaningful teacher training program for science and non-science teachers to correct conceptual difficulties in science. Therefore, it is important to develop the learning activities, which are appropriate with the nature of the concepts being constructed. Providing primary school science teachers experiences through the five steps of inductive method with: motivating the learners with inquiry questions (preparation phase), observing sets of data (presentation phase), analyzing and organizing those gathering data by determining related or contrast elements, cause-and-effect links between two or more given phenomena (comparison and abstraction phase), creating or representing what the elements being found into core concepts, common principles, mathematical formulas, general cause-and-effect relationships (generalization phase), and applying those generalizations into new situations, could promote critical thinking, the ability for inquiry, and a way for teaching science. This teaching process enables teachers to actively participate in the processes of knowledge creation related to how the experimental scientists do their work [26]. In addition, analysis of the curriculum science knowledge to be taught, identification of misconceptions or conceptual difficulties about the science content areas, identification of learning demands [29] used as a guide to planning the instructional activities are also under the constructivist learning theory that new knowledge is constructed from prior knowledge, so the prior knowledge should be considered in planning learning activities [27] and promote a social activity with meaning negotiated from multiple perspectives [28]. The cognitive and social constructivist perspectives of learning were aware in the designing of the teaching/learning activities, like Leach and Scott [29]. Based on the teacher performances, the results indicate that they had better conceptual understanding in force and motion, simple DC circuits, and astronomy concepts after participating in the instructional activities designed. Therefore, using inductive learning activities and strategies in teacher training programs can be used to promote science and non-science primary school science teachers' understanding of science concepts.

\section{Implications}

Using inductive learning methods in a teacher training program is seen as effective teaching and a learning approach that enhances primary school science teachers' understanding of the subject matter and might motivate their interest in how to sequence learning activities in science courses. However, after the inductive instructional activities were implemented, the researcher found that it was difficult to work through the content-oriented and activity-oriented plans within the limited timeline of the program. With only 6 hours for conducting each instructional activity in each content area, it is seen as a time limitation. There is also more sub activities in a topic, so to use this teaching procedure in classrooms, teachers could spend much more time to conduct learning activities and would be encouraged to do so, based on the learners they are working with at the time. Using videos to demonstrate some topics in this study were also connected to time limitations. However, students should be actively encouraged to predict what the outcomes of the demonstrations will be that would allow them to participate in the demonstration. By thinking of what they have observed and how it relates to what they are going to learn, there are greater opportunities for success. In addition, the steps of designing learning sequences need formulating a set of activities that make links to the concepts of science and learners' prior knowledge. By asking questions related to the concepts before introducing a new concept, this might encourage learners to think about what they are learning and it also assists the teacher in knowing the students' prior knowledge of the subject matter.

\section{Acknowledgements}

This work benefited from research funding by Thailand 
Research Fund (TRF) Grant No. MRG5580191, Udon Thani Rajabhat University, the Thailand Research Fund and Office of the Higher Education Commission. I would like to thank Prof. Jeffrey Nash for their editorial assistance in preparation of this manuscript.

\section{REFERENCES}

[1] K. Thiyagu. Professional Preparation of Teachers. In V.Ravi (Ed), Teacher Education. Laxmi Book Publication, Maharashtra, India, 2015.

[2] A. J. Wayne, P. Youngs. Teacher Characteristics and Student Achievement Gains: A Review. Review of Educational Research, Vol.73, No.1, 89-122, 2003.

[3] E. A. Hanushek, S. G. Rivkin. Teacher Quality. In E. A. Hanushek, F. Welch (eds.), Handbook of the Economics of Education, Vol.2, 1051-1078, Amsterdam: North-Holland, 2006.

[4] G.E. Napper-Owen, R. Marston, P. V. Volkinburg, H.Afeman, J. Brewer. What constitutes a highly qualified physical education teacher, JOPERD, Vol. 79, No.8, 26-30, 2008.

[5] K. James, P. Sammons. Effective teaching: a review of research and evidence. CfBT Education Trust, England, 2013.

[6] D.G. Borich. Effective Teaching Methods (3rd ed). Merrill and imprint of prentice Hall Englewood Cliffs, New Jersey Columbus, Ohio, 1996.

[7] L. Darling-Hammond,J. Bransford. Preparing teachers for a changing world: What teachers should learn and be able to do. San Francisco, CA: John Wiley \& Sons. 2005.

[8] S. Sarason. The predictable failure of educational reform: Can we change course before it is too late? San Francisco: Jossey-Bass.

[9] Manisha Das. Innovative Practices in Teacher Education: An Overview, International Research Journal of Interdisciplinary \& Multidisciplinary Studies (IRJIMS), Vol.1, No.4, 15-18, 2015.

[10] L. S. Shulman. Knowledge and teaching: Foundations of the new reform. Harvard Educational Review, Vol.57, 1-22, 1987.

[11] P. L. Grossman, A. E. Richert. Unacknowledged Knowledge Growth: A Re-Examination of the Effects of Teacher Education. Teaching and Teacher Education, Vol. 4, Issue 1, 53-62. (1988).

[12] S. K. Abell. Research on science teacher knowledge. In S.K. Abell, N.G. Lederman (Eds), Handbook of research on science education, Mahwah, NJ: Lawrence Erlbaum Associates, 2007.

[13] National Research Council (NRC). National science education standards. Alexenderia. VA: National Academic Press, 1996.

[14] E. Bagno, B.S. Eylon, U. Ganiel. From fragmented knowledge to a knowledge structure: Linking the domains of mechanics and electromagnetism. American Journal of Physics, Vol. 68, No.7, S16-S26, 2000.
[15] R. Duit, D. F. Treagust. Conceptual change: A powerful framework for improving science teaching and learning. International Journal of Science Education, Vol. 25, No. 6, 671-688, 2003.

[16] A. J. Wayne, P. Youngs. Teacher Characteristics and Student Achievement Gains: A Review. Review of Educational Research, Vol.73, No.1, 89-122, 2003.

[17] J.H. Wandersee, J.J. Mintzes, J.D. Novak. Learning: Research on alternative conceptions. In D. Gabel (Ed.), Handbook of Research in Science Teaching and Learning. National Science Teachers Association: MacMillan Publishing Company, 177-210, 1994.

[18] W. Sangnapaboworn. The Development of Primary Education in Thailand and Its Present Challenges: From Quantity to Quality through Effective Management. In Y. Akiko (Ed.), Universalization of Primary Education in the Historical and Developmental Perspective, Institute of Development Economies, 2007.

[19] Teachers' Council of Thailand Board, Online available from http://site.ksp.or.th/home.php?site=englishsite

[20] S. Klainin. Science education in Thailand: The development and delimas. Bangkok: The Institute for the Promotion of Teaching Science and Technology (IPST), 2012.

[21] Office of the Education Council. Monitoring and Evaluation of Thai Education Management under the national education policy in 2013.

[22] P. Siribanpitak, S. Boonyananta. The Qualifications of the Teaching Force in Thailand. In R. M. Ingersoll (Ed.), A Comparative Study of Teacher Preparation and Qualifications in Six Nations, Online available from www.cpre.org.

[23] K. Appleton. Elementary science teaching. In S.K. Abell \& N.G. Lederman (Eds.), Handbook of research on Science Education (pp. 493-535). Mahwas. NJ: Lawrence Erlbaum Associates, 2007.

[24] M. J. Prince, R. M. Felder. Inductive teaching and learning methods: definitions, comparisons, and research bases, the Journal of Engineering Education, Vol.95, No.2, 123-138, 2006.

[25] T.B. Tee. Man, Science and Religion: A quixotic quest, 2004., Online available from www.authorsonline.co.uk.

[26] R. Spronken-Smith. Experiencing the process of knowledge creation: The nature and use of inquiry-based learning in higher education. Journal of Geography in Higher Education, Vol.2, 183-201, 2008.

[27] J. M. Applefield, R. Huber, M. Moallem. Constructivism in theory and practice: Toward a better understanding, The High School Journal, Vol.84, No.2, 35-53, 2000.

[28] D. Hunter, T. Gambell, B. Randhawa. Gender gaps in group listening and speaking: issues in social constructivist approaches to teaching and learning, Educational Review, Vol.57, No.3, 329-355. 2005.

[29] J. Leach, P. Scott. Designing and evaluating science teaching sequences: An approach drawing upon the concept of learning demand and a social constructivist perspective on learning, Studies in Science Education, Vol.38, 115-142, 2002. 
[30] P. Narjaikaew. Alternative Conceptions of Primary School Teachers of Science about Force and Motion. Procedia Social and Behavioral Sciences, Vol. 88, 250 - 257, 2013.

[31] The Institute for the Promotion of Teaching Science and Technology (IPST). The Basic Education Core Curriculum B.E. 2551 (A.D. 2008): Science. Bangkok.

[32] M. B. Garcia. Focus on Teaching. Manila: Rex Book Store, 1989.

[33] P. V. Engelhardt, R. J. Beichner. Teachers' understanding of direct current resistive electrical circuits. American Journal of Physics, 72(1), 98-115, 2004.
[34] J. Baxter. Children's understanding of familiar astronomical events, International Journal of Science Education, Vol.11, No.5, 502-513, 1989.

[35] I. A Halloun, D. Hestenes. Common sense concepts about motion. American Journal of Physics, Vol.53, No.11, 1056-1065, 1985.

[36] D. P. Maloney, T. L. O’Kuma, C. J. Hieggelke, A. V Heuvelen. Surveying students' conceptual knowledge of electricity and magnetism. American Journal of Physics, Vol.69, No.7, S12-S23, 2001 